\title{
Construction of Joint Training Bases for Full-time Professional Degree Postgraduates in Local Colleges and Universities
}

\author{
Jian Wei ${ }^{a}$ \\ Graduate Education Department, Guangxi University of Science and Technology, Liuzhou, \\ Guangxi, 545006, China. \\ a781642983@qq.com
} Keywords: full-time professional degree postgraduates, joint training bases, local colleges and
universities.

\begin{abstract}
According to the requirements of our country, each college or university must strengthen the construction of full-time professional degree postgraduates joint training bases, and joint training bases have increasingly become an indispensable link for full-time professional degree postgraduates. Through the joint training bases, the postgraduates can get the training of practical abilities and achieve the training goal of professional degree. On the other hand, the enterprises and institutions that rely on the bases can also obtain more high-level technical talents to achieve the purpose of technological innovation. However, in the course of operation, there are still many problems that need to be solved step by step, and eventually achieve double-win goals.
\end{abstract}

\section{Introduction}

In the year of 2015, the Ministry of Education's “Opinions on Strengthening the Case Teaching of Postgraduates with Professional Degrees and the Construction of Joint Training Base" (No1 of the Teaching and Research Institute [2015]) clearly demanded: "The bases are set up to strengthen the practical abilities of postgraduates with professional degrees. The talent training platform established jointly with the industry, enterprises, and social organizations is the main place for professional postgraduates to carry out professional practice and an important carrier for combining production and learning. Strengthening bases construction is a basic requirement for the practice ability of postgraduates with professional degrees. It is an important guarantee for promoting the transformation of education concepts, deepening the reform of training models, and improving the quality of training." The document clearly defines the goals and requirements of the construction. Around the goals and requirements, each training unit has established a number of joint training bases through various channels, and sents professional postgraduates to the bases for practical training.

Through the cultivation of postgraduates who enter the bases, they can translate theory into practice, strengthen the cultivation of practicality and professionalism, exercise and cultivate professional literacy, enhance employment competitiveness and employment quality, and eventually become high-level professional talents. Enterprises and institutions that receive postgraduates, which rely on the bases, can get more high-level technical talents to help their technological innovation, improve $R \& D$ capabilities, and promote the conversation rate of scientific research results. At the same time, it is also possible to retain some outstanding talents as a backup force for employees. Take Guangxi University of Science and Technology as an example, postgraduates in the master's degree in translation field practice in a company in Liuzhou City. During the eight-month internship period, students used the knowledge of translation they had learned in school to help the company translate a large amount of technical materials, and at the same time, increased their own practical experience. It also saved the company nearly one million translation costs. The performance of the students was well received and affirmed by the company, and it also laid a good foundation for strengthening cooperation and students' employment in the future. It can be seen that the establishment of a joint training bases should be a double-win situation. 
Since the year of 2009, the training of full-time professional degree postgraduates has only been nine years, especially for local colleges and universities, and it is still a new thing. Therefore, there are many problems in the construction of the bases.

\section{Problems of Joint Training Bases for Postgraduates with Professional Degrees}

\subsection{Limited selection of joint training sites}

Many bases are established through mentors who are familiar with off-campus mentors or have cooperative projects. Some are not even supported by schools. The choice is narrow and it is very likely that there will be no suitable bases. In addition, the level of units relied on by the bases will also be limited, because those small companies often cannot provide enough resources to cultivate excellent professional graduate students.

\subsection{The number of postgraduates admitted to joint training bases is limited}

A number of joint training bases in most local institutions is not large, and the number of postgraduates accepted at each base is limited. Taking the joint training base for professional degree graduates of Guangxi University of Science and Technology as an example, in 2017, the two fulltime professional degree postgraduates had a total of four bases, which received 15 postgraduates. The number of students accepted by the joint training base is not large. The specific conditions are as follows:

Table.1. The Number of Students in Guangxi University of Science and Technology-postgraduates joint training bases [1]

\begin{tabular}{|c|c|c|}
\hline Name of the Bases & Cooperative Units & $\begin{array}{c}\text { The Number of the } \\
\text { Students }\end{array}$ \\
\hline $\begin{array}{c}\text { Joint Training Base for Postgraduates in } \\
\text { Technical Translation }\end{array}$ & $\begin{array}{c}\text { 1. SAIC General Wuling } \\
\text { Automobile Co., Ltd.; } \\
\text { 2. Liuzhou Caiefu Machinery } \\
\text { Co. Ltd. }\end{array}$ & 7 \\
\hline $\begin{array}{c}\text { Joint Training Base for Master of } \\
\text { Translation Postgraduates }\end{array}$ & $\begin{array}{c}\text { Liuzhou Foreign Affairs Office } \\
\text { Joint Training Base for Applied } \\
\text { Statistics Postgraduates }\end{array}$ & $\begin{array}{c}\text { Guangzhou Teddy Smart } \\
\text { Technology Co., Ltd. }\end{array}$ \\
\hline total & \multicolumn{2}{|c|}{15} \\
\hline
\end{tabular}

\subsection{Sustainability of joint incubators}

Some bases are based on projects or acquaintances. Once the projects are completed or acquaintances leave the bases, it may not be sustainable and becomes a nominal base.

\subsection{Joint Training Base Mentor Arranging and Assessment}

According to the training plans, postgraduates should implement the "double tutor" system, and on-campus mentors and off-campus mentors should jointly complete the training work. But in fact, mentors with relevant backgrounds outside the school are not easy to hire. For example, there are 15 part-time mentors outside the school's professional degree in the above university in 2017, but only 8 of them have an industry background. [1] If there are no corresponding tutors in the bases, the postgraduates are likely to become staff members, and cannot be combined with production, study and research. At the end, training base will become an internship base.

In addition, off-campus mentors are not closely related to on-campus mentors, and there are often disjointed situations, which is not conducive to the combination of on-campus theoretical learning and off-campus practice. The reason is the lack of an effective assessment system.

\subsection{Management of joint training bases for postgraduates}

Postgraduates generally enter the bases at the end of the first year, and from then on, they rarely participate in the school's activities. The school's supervision and management of graduate students is far from reaching. This situation is very unfavorable to the cultivation of graduate students. On one hand, they cannot monitor their learning and scientific research. On the other hand, they cannot master their ideological dynamics, which is not conducive to the cultivation of moral education. What is 
worse, if the management of the bases is only formal, the postgraduates' study and work at the bases will be in a state of laissez-faire, and the cultivation goals will not be completed.

\subsection{Evaluation of Joint Training Bases}

Many local colleges and universities have established bases, but they have not established an evaluation system to assess the effectiveness of the base construction. Each year, the summary can list the number of bases, students, mentors and so on. But not all bases can achieve the expected goals, and there is no systematic assessment and analysis.

\section{Research Status of Joint Training Bases for Postgraduates with Professional Degrees}

At present, there are many studies on the joint cultivation model of full-time professional degree postgraduates, among which there are not many studies on the joint training bases. Dongmei Zeng of Guangxi University conducted a study on the mode of operation. Taking Guangxi University as an example, she explored the double-win mode of operation of the schools and enterprises. [2] Jingru Li of Dalian Ocean University put forward suggestions for improving the effectiveness of training bases from the perspective of university administrators. [3] Combining the characteristics of local engineering colleges and universities, Guangdong University of Technology has established a joint training and demonstration bases for postgraduates, which has become a successful platform for combining production, study and research. Some researchers also analyze how to do a good joint training base from a specific specialty. What's more, there are also useful lessons to be drawn from foreign experience.

From the view of the research content, there are several aspects, such as the selection, management, evaluation, and assessment of the bases to build a model. From the point of the governments, schools and enterprises, some researchers try to explain how to perform their duties and do their best to build the bases.

\section{Recommendations}

For local colleges and universities, the successful experience of Guangdong Province can be said to be an example, providing ideas and ways for construction.

\subsection{The government, universities, enterprises and institutions are closely linked to build a base}

Due to the large number of enterprises, the demand for professional postgraduates in Guangdong Province is very large, so the demand for joint training bases is also very prominent. But after all, enterprises are decentralized, and minor enterprises' reception and technological capabilities may not be able to support the establishment of a base. This requires the pooling and integration of superior resources, in which the local governments play an active role. The governments have taken an active lead in linking various small and medium-sized enterprises to build postgraduates joint training bases or postgraduates workstations. At the same time, the governments also organize enterprises to conduct school-enterprise exchanges in various universities, sign agreements, and introduce required students to the bases or workstations.

After sending postgraduates to the bases, colleges and universities cannot abandon their hands. They should regularly supervise and inspect, understand the practice of the students, and give enough guidance to them. Enterprises and institutions must also seriously participate in the training of the students. They cannot simply use the students in the bases as ordinary staff. They must position the students in the identity of students, scientific research forces, and the identity of reserve staff.

\subsection{Improvement of the management system, in accordance with their respective roles and capacities}

Universities and bases cannot formulate their own management systems, and they should be linked together. After all, whether they are in school or in the bases, those are inseparable parts of postgraduate training. In order to do well in the management, colleges and universities must have corresponding departments and full-time personnel responsible for communicating the school's various work to each postgraduate, visiting the base regularly, paying attention to the daily life and ideological dynamics of the students, and checking whether they have completed training and practice 
plans. The bases must also make a person be in charge of the management of the students, such as daily attendance, practice and so on. Under the efforts of both sides, under the protection of the system, ensure that the students can successfully complete the various training links.

Before the students enter the bases, they should be mobilized to let them know what they should do, what they should not do, and what they should accomplish. Encourage them to actively test for professional qualifications in related industries.

\subsection{Selection and assessment of off-campus mentors}

The "double-tutor" system should be implemented to ensure that under the premise of two mentors on and off campus, off-campus mentors must have an industry background, otherwise the "doubletutor" system will have no meaning. The tutors in school must regularly go to the bases to study, communicate and understand the knowledge of the industry. After all, the students must finally return to schools to complete the writing of papers or investigation reports. At the same time, off-campus mentors should also go to colleges and universities in advance to understand the theoretical learning situation of postgraduates.

Off-campus mentors should be assessed, and the evaluation indicators should be formulated. The results of the work can be appropriately quantified. For example, if you have a master's degree in translation, you can use the completion of several translations as an assessment indicator.

\subsection{Establishment of a Perfect evaluation system}

Through the evaluation, you can know whether the work of the base is done well or not, and whether you have achieved the desired goals. The evaluation system includes: base conditions, financial support, teacher support, scientific research support, vocational training support, training quality, scientific research and working results, management work, etc.

\section{Conclusion}

According to the requirements of the state, the ratio of professional degree postgraduates to academic postgraduates is 1:1. Many local colleges and universities have not yet reached this ratio. After the increase in the number of people in the future, the requirements for postgraduate joint training bases will increase. We must build existing bases, continue to open up new bases, and let the bases really play their due role.

\section{Acknowledgments}

Innovation Project of Guangxi Graduate Education(JGY2015119).

\section{References}

[1]. Quality Report for Graduate Students of Guangxi University of Science and Technology in the 2016-2017 School Year.

[2]. Dongmei Zeng, Wen Xue. Research on the operating mode of joint training base for graduate students with professional degrees [J] Journal of Guangxi University (Philosophy and Social Science),2015(5), p.110-114.

[3]. Jingru LI, Yucai Hu. A Study on the Effectiveness of the Construction of Joint Cultivation Base for Graduate Students with Professional Master's Degree[J]. Education Teaching Forum, Aug, 2017(32), p. 49-51.

[4]. Yao Wang et al. Exploration and practice of off-campus practice base construction for graduate students with professional degrees [J] Electronic education, 2017(9), p. 49-52. 